\title{
Thinking Out of the Box: Fair Work for Platform Workers
}

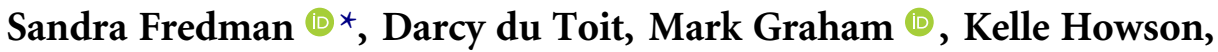 \\ Richard Heeks ${ }^{\circ}$, Jean-Paul van Belle, Paul Mungai and Abigail Osiki
}

\section{PART I INTRODUCTION}

The burgeoning gig economy largely operates outside of existing labour standards, mainly because in most countries workers are classified as self-employed rather than as employees. Until now, much legal effort has been focused on bringing platform workers within the scope of labour law by proving that they fit the definition of employee or worker, which functions as the gateway to employment rights. This has yielded some positive outcomes, particularly in exposing sham self-employment. However, this approach is limited, not least because platforms are adept at reconfiguring their conditions of work to avoid the legal definition of employee, or at fragmenting their corporate structure to evade the jurisdiction of courts in the region where workers in fact find themselves. By contrast, not enough attention has been paid to how labour law standards, fashioned for the 'employee' paradigm, should be reshaped to meet the needs of platform workers regardless of their employment status.

It is these challenges that the Fairwork project in South Africa aims to address. It brings together social scientists and lawyers to establish novel means of developing

\footnotetext{
${ }^{\star}$ Sandra Fredman, Professor of the Law of the British Commonwealth and the USA, Oxford University. Email: sandra.fredman@law.ox.ac.uk

Darcy du Toit, Emeritus Professor at the University of the Western Cape. Email: darcy@bchc.co.za

Mark Graham, Professor of Internet Geography, Oxford Internet Institute, Oxford University, Director Fairwork Foundation. Email: mark.graham@oii.ox.ac.uk

Kelle Howson, Postdoctoral researcher, Fairwork Foundation, Oxford Internet Institute, Oxford University. Email: kelle.howson@oii.ox.ac.uk

Richard Heeks, Chair in Development Informatics, Global Development Institute, Director, Centre for Development Informatics. Email: richard.heeks@manchester.ac.uk

Jean-Paul van Belle, Professor, Department of Information systems, University of Cape Town. Email: jeanpaul.vanbelle@uct.ac.za

Paul Mungai, Research Fellow, Fairwork Foundation, Department of Information Systems, University of Cape Town. Email: paul.mungai@uct.ac.za

Abigail Osiki, Previously Post-Doctoral Researcher Fairwork Foundation, University of Western Cape. Email: osikiabigail@gmail.com
} 
appropriate labour standards as well as to test alternative means of compliance, using both reputational means and legal change. Funded by the ESRC Global Challenges Research Fund, the project has created a ranking scheme to evaluate the working conditions of digital platform workers. Drawing inspiration from the Fairtrade and Living Wage campaigns, it aims to create pressure on platforms to improve working conditions through a public ranking system which scores selected platforms according to their record under five broad principles: fair pay, fair conditions, fair contract, fair management and fair representation. Such scores, as well as appealing to the reputational concerns of platforms, can be used by workers to negotiate for better working conditions, and by consumers. Concurrently, we aim to use the empirical work to develop standards capable of being given legally binding force.

This paper addresses a key issue arising from the project. Given that the limited impact of legal regulation has prompted action to be taken outside of labour law in this area, what, if any, is the ongoing role of labour law? It will be shown that there is an important two-way interaction between rating standards and legal regulation. Only through ensuring that this interaction remains and grows, will both labour law and rating principles be capable, ultimately, of advancing decent work for platform workers. Part II examines pathways to change, setting out the project and its overall rationales. Part III examines the substance of the rating principles and their interaction with legal employment rights. Part IV touches on how rating principles might be translated into legally binding standards capable of responding to the needs of platform workers. It concludes that they should be seen as crucially complementary.

\section{PART II PATHWAYS TO CHANGE}

By platform work, we mean work which is organized and mediated by digital labour platforms such as Uber. ${ }^{1}$ It is common for platforms to classify workers as self-employed and therefore outside of any labour law protections. Litigation contesting this classification has had mixed results, usually depending on how the court construes the extent to which the platform has control over its workers. ${ }^{2}$ This leaves open multiple

$1 \quad$ N Srnicek, Platform Capitalism (Polity Press 2017), 43. Our research focuses on geographically-tethered platform work rather than cloudwork.

2 An employment relationship was found in Douglas O’Connor v Uber Technologies, No. C-13-3826 EMC, March 11, 2015 (Northern District of California); Dynamex v The Superior Court of Los Angeles County, Ct.App. 2/7 B249546 (The Supreme Court of California). See also cases from Cour de Cassation (French Supreme Court), November 28, 2018 https://www.soulier-avocats.com/en/reclassification-of-thecontract-between-a-delivery-rider-and-a-digital-platform-a-strong-message-sent-by-the-cour-decassation/; Sao Paulo Appellate Court, August 28, 2018 https:/www1.folha.uol.com.br/internacional/en/ business/2018/08/uber-drivers-are-employees-court-decides-in-brazil.shtml; Valencia Social Affairs Court, June 2019 https://phys.org/news/2019-06-spanish-court-deliveroo-riders-employees.html; Madrid Court, July 2019 https://www.france24.com/en/20190723-madrid-court-rules-deliveroo-ridersare-employees. An iindependent contractor relationship was found in the following cases: Michael Kaseris v Rasier Pacific, V.O.F., [2017] FWC 6610 (Australian Fair Work Commission); Pallage v 
opportunities for platforms to recast the nature of the relationship to evade these tests, leaving it up to workers to mount further legal challenges. All the workers in the Fairwork study were classified by the relevant platforms as self-employed.

The limits of labour law's ability to fill this regulatory space prompts us to ask whether there are other ways of achieving decent work for platform workers. Teubner has famously argued that the 'command and control' nature of law triggers the 'regulatory trilemma': it either prompts strategies of resistance from the regulated body; or risks damaging the latter; or brings the law itself into disrepute. ${ }^{3}$ This is clearly demonstrated when platforms such as Uber re-characterize their relationships with workers specifically to avoid attempted legal regulation. This suggests that in addition to command-andcontrol, other ways are needed to prompt change in organizations. This is not, of course, a new insight for labour law, where the ability of law to control capital in favour of workers has always been regarded with fundamental scepticism. ${ }^{4}$ The traditional response is to marginalize command-and-control legal regulation and instead prioritize autonomous norms arising from collective bargaining between capital and organized labour. In this way, the power of capital will be counterbalanced with the power of organized labour. There have been some valiant attempts to organize platform workers. ${ }^{5}$ However, because platform work is decentralized and fragmented and workers are often in competition with each other for work, collective organization is difficult to achieve.

What other possibilities, then, are there for prompting change within organizations to achieve decent work for platform workers, including fostering collective organization and eventually changes in the law? The first step is to move away from the assumption that compliance can only occur through a 'classic deterrence' approach, or 'a mechanism of deterrence which works via commands against misconduct spelled out in legal rules, monitoring of compliance by a state regulatory agency, and application of punitive sanctions for breach'. ${ }^{6}$ Regulatory studies have shown that this does not properly describe how successful regulation should operate. Instead of discrete legal measures, studies have turned to the notion of social control, functioning through a web of influences. ${ }^{7}$

Rasier, [2018] FWC 2579 (Australian Fair Work Commission); Razak v Uber, CA No. 16-573 (April 11, 2018) (US District Court for the Eastern District of Pennsylvania); Lawson v Grubhub, Case No. 15-cv05128-JSC (February 8, 2018) (District Court of the Northern District of California); Vega v Postmates, 2018 N.Y. Slip Op. 4610 (June 21, 2018) (Appellate Division of the Supreme Court of New York); Inake v Deliveroo, 6622665 CV EXPL 18-2673, (July 23, 2018) (Court of First Instance, Amsterdam). A third category of worker relationship was found in Uber BV v Aslam [2018] EWCA Civ 2748 and Addison Lee v Lange [2019] I.C.R. 637 (UK Employment Appeal Tribunal). With thanks to Gautam Bhatia for his research on this.

3 G Teubner, 'Substantive and Reflexive Elements in Modern Law' (1983) 17 Law and Society Review 239. O Kahn-Freund, Labour and the Law (2nd edn, Stevens 1977).

5 C Cant, Riding for Deliveroo (Polity Press, 2020); J Woodcock and M Graham, The Gig Economy: A Critical Introduction (Polity Press 2020); ibid.

6 C Parker and J Braithwaite, 'Regulation' in M Tushnet and P Cane (eds), The Oxford Handbook of Legal Studies (OUP 2005), 129.

7 Ibid 129. 
Most importantly, empirical research has shown that in assessing the disadvantages of non-compliance, individuals or management do not only consider the direct costs, such as the size of a possible fine. In addition, they afford great significance to the indeterminate costs of bad publicity, and to maintaining or advancing corporate reputation. ${ }^{8}$ Indeed, studies of organizational behaviour have suggested that informal sanctions, including negative publicity and public criticism, can have a greater deterrent impact than formal legal sanctions. ${ }^{9}$

At the same time, it is clear that there is a need for background legal sanctions, to bind recalcitrant actors who have little need for reputational uplift, and to reassure those who do comply that they will not be undercut. Ayers and Braithwaite's wellknown regulatory pyramid suggests that regulation works best when it begins with persuasion or cooperative strategies, and escalates up the pyramid to warnings and eventually to legal sanctions of increasing levels of intensity. ${ }^{10}$ Although it has been critiqued and modified in many ways, this approach remains highly influential and has been applied by governments and regulators. ${ }^{11}$

Our project therefore works in two dimensions: we appeal to the influence of reputation, publicity and consumer power, ${ }^{12}$ while simultaneously shaping appropriate legal standards and exploring avenues to achieve their adoption. We use a ranking system rather than a pass-fail certification to reflect the many-facetted nature of decent work and to create a publicly available record of the standards of work provided by specific platforms. Comparing platforms' scores publicly on a league table aims to incentivise them to improve their ranking.

The challenge is to provide rating scales which can underpin standards of decent work in this complex domain, while also giving meaningful incentives to platforms to comply and informing changes in the legal structure. Platforms are scored out of ten points, based on five principles of fair work: fair wages, fair conditions, fair contracts, fair management, and fair representation. Each principle is broken down into two points, one at a more basic level of protection, and the second at a higher level. The ranking principles have been carefully fashioned, with inputs from labour lawyers, platform managers, platform workers, government officials and other key stakeholders.

Evidence for scoring is drawn from three sources. We begin with desk research, to gain information about the platform, how it operates and the terms and conditions visible to the public. Secondly, we interview platform managers, asking them to provide evidence for each point on the ranking system. This also opens up a dialogue

$8 \quad$ Ibid 131.

9 R Paternoster and S Simpson, 'Sanction Threats and Appeals to Morality: Testing a Rational Choice Model of Corporate Crime’ (1996) 30 Law and Society Review 549; J Braithwaite, Restorative Justice and Responsive Regulation (OUP 2002), 106.

10 I Ayers and J Braithwaite, Responsive Regulation (Oxford University Press 1992), 35.

11 R Baldwin and J Black, 'Really Responsive Regulation' (2007) LSE Law Society Economy Working Papers.

12 M Graham and others. 2020. The Fairwork Foundation: Strategies for Improving Platform Work in a Global Context. Geoforum. https://doi.org/10.1016/j.geoforum.2020.01.023 
for the platform to agree changes to better achieve the Fairwork principles. Where platform managers do not agree to interview, scoring is based on the other two sources. Thirdly, we interview workers, the aim being to interview six to ten workers for each platform. For the 2020 ranking in South Africa, 74 workers were interviewed across eleven platforms. These are not representative; instead, they function to confirm or refute evidence produced by platforms. For example, worker interviews showing that they are paid less than the minimum wage can be used to deduct points, but interviews showing the opposite could not confirm that all workers on the platform are paid the minimum wage. ${ }^{13}$

Platforms are only awarded a point when they can satisfactorily demonstrate implementation of the Fairwork principles. Failing to achieve a point does not mean that a platform does not comply, but that it was not able to demonstrate compliance. Points are not awarded if there are ambiguities or contradictions between what platforms and workers report. Where there is no data, the score is zero.

The goal is to publish yearly rankings. Fieldwork has now been carried out to apply the second annual rankings to platforms in South Africa and a league table of scores is publicly available. ${ }^{14}$ Eleven platforms were scored during the second year. Of these, there were two ride-hailing platforms (Uber and Bolt), two domestic work platforms (Domestly and SweepSouth), one digital recruitment platform (NoSweat), one trade directory platform (GetTOD), one micro-work and mystery shopping platform (M4Jam) and four delivery platforms (Picup, UberEats, Mr D, and Orderin). Both annual league tables show platforms scoring across a wide range. In the second year, the highest-scoring platforms, NoSweat, GetTOD and SweepSouth, achieved 8 out of 10 , while the lowest, $\mathrm{Mr} \mathrm{D}$, received 0.

After two annual scoring rounds, it is clear that the appeal to reputation has led some of the platforms to engage further with the project and implement changes. In our second year of rating, seven out of eleven platforms engaged in an iterative process with researchers and provided evidence to support their scores. Two companies, GetTOD and NoSweat, wanted to do better in encouraging worker voice on the platform (the fifth principle), and thus agreed to adopt a worker-facing policy to facilitate collective representation and bargaining. These platforms have also gone beyond the minimum wage requirement set in the first principle, to guarantee workers a living wage. Other platforms have codified disciplinary and grievance procedures in their terms and conditions, ensuring due process for workers. Yet others have already indicated their desire to improve their position on the league table next year, and proactively approached Fairwork for advice on how to do so. 


\section{PART III DEVELOPING DECENT WORK STANDARDS FOR PLATFORM WORKERS}

As well as examining alternative pathways to change, a key contribution of the project is its formulation of the standards themselves. The challenges of crafting appropriate standards of decent work for platform workers are well-known. Labour law standards generally have a typical 'employee' in mind-working full-time, with defined hours in a defined workplace with other workers and clear lines of management. Platform workers generally exhibit very different characteristics. Their hours of work are fluid. The workplace (the car, bicycle or computer) is often owned or hired by the worker rather than the platform. For domestic workers, it is a different private house each day. Lines of management are complex and often obscure; and customer reviews play a central role in performance evaluation. Workers bear almost all the costs of their work, such as the mobile phone, data services, vehicle, insurance, fuel, supplies, and safety equipment.

Until now, much legal effort has been focused on squeezing platform workers through the gateway to employment rights by demonstrating that they fit the definition of 'employee' or 'worker'. This wrongly assumes that, once through the gateway, employment standards can be applied to platform workers in identical forms to those applying to standard employees. It also leaves out of account the right to decent work of workers who cannot get through the gateway, or prefer not to be. Fairwork's formulation of the rating principles therefore consciously aims to provide standards which are appropriate for the specific needs and situation of platform workers. This is not, however, done in a vacuum. Legal standards are the starting point, which, matched with the experience of platform workers, produce a changed but recognizable set of standards. Ultimately, the objective is for these new standards to be read back into existing labour law to ensure decent work for all, regardless of how they are characterized. This process is elaborated below.

\section{Fair Pay}

The starting point is to extend the statutory minimum wage to platform workers irrespective of the employment status of the worker. The first point is awarded if the platform pays at least the minimum wage, or there is a policy requiring payment above this level. We address the specific situation of platform workers by including in the minimum wage calculation both direct hours and indirect hours, such as travelling to a task or waiting between tasks. ${ }^{15}$

The second point is specifically responsive to the fact that platform workers are largely responsible for their own costs. Gross weekly pay might appear to be above the minimum wage, but work-related costs can substantially reduce this amount.

15 Uber BV v Aslam [2018] EWCA Civ 2748; S Fredman and D du Toit, 'One Small Step Towards Decent Work: Uber v Aslam in the Court of Appeal' (2019) 48 Industrial Law Journal 260. 
Average pay levels in our second year South African sample were R48 per hour, signifi-

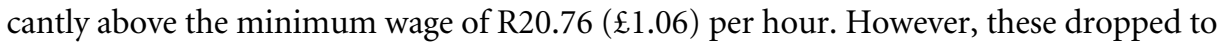
an average of R21 per hour once work-related costs were taken into account. This was particularly problematic for delivery drivers: over 75 per cent of those we interviewed were earning below the minimum wage after costs. Some were in fact losing money on longer delivery drops as costs exceeded payment. ${ }^{16}$ Roughly one third of interviewees were earning less than minimum wage in net terms. ${ }^{17}$ Thus, to achieve the second point, a platform must pay the minimum wage plus costs. To establish a threshold, the platform is required to provide an estimate for work-related costs, which are then checked through interviews with workers.

On the second year's rating, ten of the eleven platforms were awarded the first point, the outlier being Mr D. ${ }^{18}$ However, this should be seen in the light of the shockingly low rate of hourly statutory minimum pay in South Africa, which is a mere R20.76, or $\mathfrak{E} 1.06$. For domestic workers, it is even lower, at R15.57 an hour, or 80 pence. ${ }^{19}$ Only six platforms were awarded the second point, with Uber, UberEats, Bolt, and Orderin joining $\mathrm{Mr} \mathrm{D}$ in being unable to demonstrate compliance.

This led us to reconsider the standard for fair pay. Given the costs burden borne by platform workers, it no longer made sense to award a point for minimum pay before costs are deducted. It has therefore been proposed that costs should be included in the first point, so that only platforms who pay the minimum wage after costs are awarded this point. For the second point, our proposal is to turn to the concept of a living wage. This untethers us from existing legal frameworks, necessitating a formula for a living wage which is feasible and considered legitimate by platforms. As previously noted, two South African platforms have already adopted living wage policies following engagement with Fairwork. We have drawn on the conception of a living wage as remuneration sufficient for a basic but decent standard of living for a worker and their family. ${ }^{20}$ There are several ways to calculate the living wage: putting these sources together, we have come up with the figure of R6,800 per month for $2020 .^{21}$ The suggestion is that this should be the standard for the third year.

R Heeks and others, (2019) Evaluating Platform Work Against Decent Work Standards: Evidence from the South Africa Fairwork Project, paper presented at Post-Automation symposium, University of Sussex, 11-13 September 2019.

17 Note, however, that higher paying platforms are under-represented in our interviews.

18 But see Competition Commission South Africa Market Inquiry into Land Based Public Passenger Transport' (http://www.compcom.co.za/wp-content/uploads/2020/02/PROVISIONAL-REPORT-ON-E-HAILINGAND-METERED-TAXIS-19February2020-NON-CONFIDENTIAL-VERSION1.pdf), para 7.5 for evidence from 2018 that some Uber drivers were sometimes earning less than the minimum wage. Our evidence was from 2019.

19 National Minimum Wage Act; Government Gazette No 11041 dated 17 February 2020.

20 https://www.globallivingwage.org/about/what-is-a-living-wage/; https:/www.ilo.org/dyn/normlex/en/f? p=NORMLEXPUB:12100:0::NO::P12100_ILO_CODE:C131

21 R Heeks and others, A Living Wage for South African Platform Workers (Fairwork 2019). https://fair.work/ a-living-wage-for-south-african-platform-workers/ 


\section{Fair Conditions}

This principle focuses on health and safety. Defining this for platform workers is complex, since platforms generally transfer the cost of acquiring and maintaining a 'workplace' to the worker, whether it be in the form of a vehicle, bicycle, or computer at the worker's home. Principle 2 is therefore not bound to the notion of workplace. Instead, for the first point, the platform should identify the task-specific risks that arise for the worker and demonstrate that there are policies or practices in place that protect workers from these risks. In South Africa, a major risk is from crime and road accidents. Problems with clients were also identified in the fieldwork, as well as dangerous pets and allergies for domestic workers. ${ }^{22}$ For the second point, platforms should go beyond basic risk mitigation and take proactive measures to protect and promote the health and safety of workers. This must be evidenced through a documented policy. Seven platforms were awarded the first point. SweepSouth and Uber received an additional point for proactive measures, such as making available affordable health insurance policies and an in-app panic button.

\section{Fair Contracts}

Access to a statement of terms and conditions of work is a key right for standard employees. ${ }^{23}$ For platform workers, simply accessing their terms of employment remains a problem. Even more challenging is the fact that the digitally-mediated nature of the work makes it very easy to change these terms. Workers report that they are regularly presented with updated terms and conditions and are required to signify consent before they can log on to start work. The conditions are long and complex, and given the trade-off between working and spending time reading the terms, the choice is invariably to simply agree.

To obtain the first point, therefore, the platform must show that terms and conditions are transparent, concise, and provided to workers in an accessible form. Nine platforms provided workers with continual access to their contract. Some, including NoSweat and Picup, had made a particular effort to reduce overly complicated language. For the other two-Bolt and Mr D, we could not find evidence that workers were able to read their contracts after signing by tick-box.

The second point attempts to address the widespread misclassification of workers as self-employed. To obtain this point, a platform must accurately characterize the nature of the worker's relationship, assessed using criteria taken from the South African definition of employee. ${ }^{24}$ Given the extent of contestation of this definition in courts, this has been challenging to determine. Even more challenging are cases when the

Heeks et al, above n 15 .

See e.g. UK Employment Rights Act 1996, s.1; SA Basic Conditions of Employment Act 1997, (BCEA) s33.

BCEA, s1. 
characterization as self-employed is accurate. To devise an alternative criterion for contractual integrity, we decided to focus on the widespread practice by platforms of limiting their own contractual liability by incorporating wide-ranging exemption clauses in terms of service. For this, we drew from the principle of limiting unfair contract terms in consumer contracts. ${ }^{25}$ Thus, where workers are genuinely self-employed, the platform must evidence that terms of service are free of clauses which unreasonably exclude platform liability.

All the workers interviewed were formally classified as self-employed. Yet the large majority exhibited clear signs of employment. As many as 41 interviewees worked for only one platform and were dependent on it economically. The workers were also under a significant degree of control or direction from the platform, and it was easily arguable that the app represented an important part of the 'tools of the trade' for the purposes of the definition. This misclassification of the workers was reflected in the fact that only two of the platforms was awarded the second point under the contract principle. ${ }^{26}$ Nevertheless, of the 29 workers who responded, 16 preferred to be seen as independent contractors. This could be because they conflate self-employed status with the flexibility which they value, even if it is illusory in practice, or because they have imbibed the rhetoric of the platform economy, and regard themselves as entrepreneurs. This reinforces the need to fashion decent work standards for all workers, regardless of classification.

\section{Fair Management}

Reflecting the need to capture fair procedures, the first point is awarded if there is evidence of documented processes through which workers can be heard, appeal decisions affecting them and be informed of the reasons for decisions. The platform interface must feature a channel for workers to communicate with the platform and a process for workers to appeal disciplinary decisions or deactivations. In the case of deactivations, the appeals process must be available to workers who no longer have access to the platform. Six platforms were awarded this first point. In relation to the other platforms, some workers had experienced arbitrary deactivation, while others did not have access to an appeals process through the platform interface. Some interviewees reported that although channels of communication existed, platforms were slow to respond or unresponsive.

The additional point under this heading concerns equity in the management process. To achieve this point, there must be evidence that the platform is actively

UK Unfair Contract Terms Act 1977.

GetTOD appeared to exercise no specific control over the manner of performance and did not use customer reviews to deactivate or penalise workers, and NoSweat appeared genuinely limited to facilitating contact and ensuring payment. This contrasts with the German study, which finds that many workers are accurately classified as employees. 
seeking to prevent discrimination against workers from disadvantaged groups. In the first year, this also included the right to be informed of data. Only four platforms were awarded this point and all achieved it in relation to fair data collection.

For the second year, these results led us to consider how the criteria could be more responsive to platform workers' experience, particularly in relation to the use of algorithms, the risk of discrimination by third party consumers and the high degree of gender segregation. The revised ranking principle thus has five criteria. Firstly, there should be a policy which guarantees that the platform will not discriminate against persons on the grounds of race, gender, sex, sexual orientation, gender identity, disability, religion or belief, age or any other status which is protected against discrimination in local law. ${ }^{27}$

The second criterion aims to address the particularly challenging issue of gender segregation. There is a high degree of gender segregation among the platforms we assessed, with the delivery and ride-hailing platforms being overwhelmingly male and the domestic worker platforms overwhelmingly female. To respond to this, the second criterion requires that, where there is significant under-representation of a disadvantaged group, the platform should have a plan to identify and remove barriers to access by persons from that group, resulting in improved representation. A good illustration is an Indian food-delivery platform reported to have specifically attempted to recruit more women. ${ }^{28}$ Having identified obstacles to recruitment of women as including the dangers of the job, the absence of a women-friendly environment and the need for specific training, it reportedly identified 'safe zones' for women to operate in and allows them to complete their deliveries by $6 \mathrm{pm}$. In addition, it is putting in place a dedicated helpline for any concerns, and appointing more women in managerial roles. It claims to have hired 2000 women under this policy.

The third criterion requires the platform to do more than simply have a policy on non-discrimination. It must also take practical measures to promote equality of opportunity for workers from disadvantaged groups, including reasonable accommodation for pregnancy, disability, and religion or belief. We address algorithms in the fourth criterion: if algorithms are used to determine access to work or remuneration, these should be transparent and should not result in inequitable outcomes for workers from historically or currently disadvantaged groups.

Addressing the risk of customer discrimination is challenging. The platform itself cannot be held to be responsible for users' discriminatory policies. Instead, according to the fifth criterion, the platform must have mechanisms to reduce the risk of users discriminating against any group of workers in accessing and carrying out work. A platform could require users to sign up to its ethic of non-discrimination when they use the platform; encourage workers to rate users, including in relation to non-discrimination; give clear support to workers' experiencing discrimination and, where possible, refuse to 
continue to supply services to users who have been discriminating against workers. For example, in India, a food delivery platform reportedly refused to give a refund or provide an alternative rider when a user objected to a receiving their order from a Muslim delivery rider. $^{29}$

In the second year, three South African platforms achieved this point-SweepSouth, Picup, and M4Jam. Picup was able to evidence initiatives to recruit more women couriers, while M4Jam could show that equity was inherent to its ethos; the platform was set up as a way to extend economic opportunities to disadvantaged communities, and has a majority of black women workers.

\section{Fair Representation}

There are numerous obstacles to collective organization for platform workers. Not only do workers often work alone; but they are frequently in competition with each other for scarce work. Platforms can easily deactivate workers they regard as disruptive. Thus to obtain the first fair representation point, there must be no evidence of freedom of association being prevented by the platform, or of a refusal by the platform to communicate with designated representatives of workers. Workers should not be subject to detriment or discrimination for organizing and associating with one another. In addition, a documented process through which worker voice can be expressed should be evidenced. Six platforms received the first point for fair representation.

The second point is more demanding. It requires the platform to publicly recognize an independent, collective body of workers; as well as not having refused to participate in collective representation or bargaining. Where such organizations do not exist, the platform must sign a public statement of its willingness to recognize a collective body of workers or trade union. None of the platforms recognized a union or any other collective body, However, two formally indicated their willingness to engage with such a body. One posted a statement to this effect on its website, and another encoded it in its contract. While these efforts are encouraging, the overall absence of representation is particularly concerning. Without the ability for workers themselves to articulate, demand and monitor decent work standards, other methods of implementation, both through public rating and legal rights, will remain limited.

Interviews with workers revealed an even lower level of collective organization. The nature of the work made an important difference. None of the NoSweat freelancers had met up with others, either physically or within a chat group, a finding which is consistent with the relative isolation of digital gig workers reported elsewhere. ${ }^{30}$ Domestic workers were similarly isolated. They rarely had an opportunity to physically meet each other as a group. Their WhatsApp groups were run by the platform, making it impossible to have 
independent interaction. By contrast, delivery and taxi drivers have waiting areas where they are able to congregate, and most were in chat-groups specific to their platform and nationality. The content of interaction was more likely to be about everyday aspects of the work outside the control of the platforms, such as warnings about traffic or police, tips on good areas or times to get business or help with repairing cars or bikes. Of the minority of interactions relating directly to work conditions, levels of payment dominated. This reflected the foremost demand of platform workers for better pay. Official collective representation was almost non-existent. However, we found some unconventional examples of worker organization. A number of delivery drivers we talked to belonged to a 'stokvel', or a self-run savings group where members make regular contributions of a small amount to a shared account and the group decides how the money is spent. In this case, the funds are paid out as compensation for loss of income if one of the group is injured on the road. In some cases we heard funds had gone towards supporting the families of drivers who had been killed.

One notable finding was the general view of interviewees on unions. In the first year, only three out of 70 workers expressed an interest in joining a union, whereas in the second year this was true for more than half the workers interviewed. This is a striking increase and could indicate a growing consciousness of the potential of collective action among platform workers.

\section{PART IV: FROM RATING PRINCIPLES TO LEGALLY BINDING STANDARDS}

To what extent then can the experience of rating principles be used to frame legally binding standards? Only the beginnings of a response can be provided here. So far as fair pay goes, there is already some precedent in the UK for including waiting hours in determining minimum pay, ${ }^{31}$ and this should be generalized to platform workers. Likewise, it has been accepted that time spent by workers who travel from one assignment to the next during the day is counted as time when the minimum wage is payable. $^{32}$ Where the law does need to move beyond existing boundaries to accommodate platform workers is in recognizing that minimum pay should be calculated after costs have been taken into account.

Similarly, health and safety protection requires adaptation of existing legal frameworks configured around a conception of a place of work under the employer's control. ${ }^{33}$ A particularly helpful precedent is the ILO Violence and Harassment Convention 2019 (C190), which protects 'workers and other persons in the world of work ...

31 Uber BV $v$ Aslam above n 15.

32 Department for Business, Energy \& Industrial Strategy National Minimum Wage and National Living Wage: Calculating the minimum wage (2019) https://assets.publishing.service.gov.uk/government/ uploads/system/uploads/attachment_data/file/835794/calculating-minimum-wage-guidance-april-2019. pdf accessed 18 October 2019, p. 36.

33 See e.g. UK Health and Safety at Work Act 1974, s.2(2)(d). 
irrespective of their contractual status.' Protection under the Convention extends not only to the workplace, but to all places where workers take rest or meal breaks, workrelated trips, commuting to and from work and through work-related communications (including ICT).

It is in the area of contract that there is particular scope for creative development to address the specific concerns of platform workers. The ranking principles require platforms to make the workers' contract available, but do not specify the content. Legal provisions should go further and set out what specific details the contract should contain. ${ }^{34}$ Furthermore, the platform should not just be named in the contract, but should be a legal entity within the jurisdiction in which workers' activities (e.g. driving) take place. This would avoid claims by the platform to be based in a different jurisdiction for the purposes of legal liability. ${ }^{35}$

Nor is it necessary to remain within the bounds of employment law. Contract law has useful elements which could be drawn on to regulate the relationship between platforms and platform workers. One example could be to extrapolate from consumer protection legislation, which regulates terms which are unfair or unreasonable. ${ }^{36} \mathrm{~A}$ further well-recognized contractual principle is that of unconscionability. This principle was directly relied on in Heller $v$ Uber, ${ }^{37}$ where the Supreme Court of Canada held that an arbitration clause requiring all disputes to be settled in the Netherlands was unconscionable. The doctrine of unconscionability permits a Court to strike down a contractual clause where there is clear inequality of bargaining power, leading to a bargain which unduly advantages the stronger party or unduly disadvantages the more vulnerable. Both these criteria were fulfilled in this case. There was clearly inequality of bargaining power: Heller, a food delivery worker in Toronto, was in no position to re-negotiate the standard-form contract presented to him by Uber. Moreover, the arbitration clause clearly unduly disadvantaged Heller, who could only resolve a dispute with Uber by paying a large up-front administrative fee, amounting to almost his whole annual income, leaving aside the cost of travel, accommodation, legal representation and lost wages. ${ }^{38}$

In relation to fair management and non-discrimination, the role of algorithms is a key challenge for future regulation. There should be at least a legal requirement that workers be made aware of the criteria which are used and how they are used. From the other direction, our fieldwork demonstrated clearly that reputational pressure is not sufficient to be sure that internal processes might not be fully implemented. They need to be backed up by the possibility of external enforcement through access to a

37

38

See UK Employment Relations Act 1996, s.1.

Contrast NUPSAW obo Mostert v Uber South Africa Technology Services (Pty) Ltd, Uber B. V. \& Uber International Holding B.V. WECT 18234-18, 31 May 2018 (South African Labour Court) and Uber BV v Aslam above n 14 and see Fredman and du Toit, above n 14 .

See e.g. the UK Unfair Contract Terms Act and the South African Consumer Protection Act.

Uber Technologies $v$ Heller 2020 SCC 16 Supreme Court of Canada.

Ibid; paras $53 \mathrm{ff}$. 
fair and accessible dispute resolution mechanism at no cost or at an affordable cost to the worker.

Finally, so far as fair representation is concerned, much thought still needs to be given to ways of facilitating collective representation, and protecting individuals against victimization. This is one area where technology can be enabling.

\section{PART V: CONCLUSION: COMPLEMENTARY PATHWAYS TO CHANGE}

It is clear that we have had some positive impact in persuading platforms to change some of their practices as a result of exposure to the rating principles. The rating principles are also helpful in providing the basis for legal regulation of platform work which responds to the specific needs and characteristics of this kind of work. It is now time to take the next steps, to generalize these principles in the form of binding legal standards.

\section{FUNDING}

The research reported in this paper has been funded by the ESRC GCRF Fund ES/S00081X/1.

\section{ORCID}

Sandra Fredman (D) http://orcid.org/0000-0002-4132-1164

Mark Graham (D) http://orcid.org/0000-0001-8370-9848

Richard Heeks (D) http://orcid.org/0000-0002-4551-2208 